\title{
Oceanography
}

CITATION

Mix, A.C. 2017. Planning the future of ocean sciences. Oceanography 30(3):5, https://doi.org/10.5670/oceanog.2017.302.

$\mathrm{DOI}$

https://doi.org/10.5670/oceanog.2017.302

COPYRIGHT

This article has been published in Oceanography, Volume 30, Number 3, a quarterly journal of The Oceanography Society. Copyright 2017 by The Oceanography Society. All rights reserved.

USAGE

Permission is granted to copy this article for use in teaching and research. Republication, systematic reproduction, or collective redistribution of any portion of this article by photocopy machine, reposting, or other means is permitted only with the approval of The Oceanography Society. Send all correspondence to: info@tos.org or The Oceanography Society, PO Box 1931, Rockville, MD 20849-1931, USA. 


\section{Planning the Future of Ocean Sciences}

In my previous column (June 2017) I wrote about the history of ocean sciences funding, focusing on the Ocean Sciences Division at the US National Science Foundation (NSF) as an example. It notes long-term budget erosion, and suggests that if we are going to reverse this trend, we need to create a viable implementation plan that demonstrates the real value of oceanography.

I firmly believe that ocean science and technology are more important than ever. We need to address ocean issues that have worldwide consequence, including the ocean's role in climate change, sustainability of environments and ecosystems under human impacts, appropriate long-term use of resources from the sea, technology development and economic opportunities related to the ocean, the scientific basis for global security, and other ocean-related issues that transcend specific fields, agencies, or national boundaries. It is time to put some ideas on the table. It is time to make a plan.

So what should we do? First, we need to start talking. I envision this conversation as an expanded collaboration between the United States and non-US communities; there are ocean sciences research assets in many countries. Just as the high-energy physics community leverages infrastructure among nations, ocean sciences could, too (e.g., sharing expensive assets like ships).

To be sure, ocean scientists have worked across national boundaries for decades-in this regard, scientists are mostly apolitical and go where the interesting problems lead them. We have some good examples of large shared efforts. These are mostly parallel funding efforts with trans-national coordination (e.g., Joint Global Ocean Flux Study, World Ocean Circulation Experiment), but there are some that have comingled funds and co-supported facilities and science implementation (International Ocean Discovery Program). Nevertheless, for the most part, national funds pay for national programs, and these programs are sometimes at least partially redundant in various countries. Some redundancy can be a good thing-replication of results confirms significance of findings. But we might think about how much duplication of effort is really needed.

An implementation planning process could encourage community building; support the development of early career scientists; enhance interdisciplinary, interagency, and international collaborations; and provide vehicles for connections between government, academic, and private-sector ocean sciences. We need diversity of thought as we plan, and this requires diversity of people; scientists and stakeholders of all kinds in both developed and developing nations must be involved. An inclusive process will increase access and effectiveness of ocean science and technology on a global scale.

We already have a start at planning, at least at the strategic level. For example, the US National Research Council's Sea Change: 2015-2025 Decadal Survey of Ocean Sciences (NRC, 2015) was commissioned by NSF in 2013 to review the changing nature of ocean sciences and its funding structures and to propose promising themes worth addressing in the coming decade. Other nations have published similar framework documents, for example, in the UK, Scanning the Horizon (Kennedy and Liss, 2013), and in Europe, Eurocean 2020 (McDonough and Calewaert, 2010). In order to implement community goals, we must engage the whole of the ocean science community in an open, inclusive, bottom-up process.

My hope is that the global ocean sciences community will not retreat in the face of political and budget pressure but instead will join together to craft a synthesis of current knowledge and to shape a productive future agenda with a specific action plan. I hope we can encourage transdisciplinary innovation, with an eye toward incorporating rapidly evolving technologies into rigorous scientific frameworks. We need concrete mechanisms for retaining early career scientists and empowering them to envision the future of the field. Universities can step up to some extent in this area, acknowledging the difficulty of starting careers on "soft" (grant-funded) money. With a goal of helping to encourage young scientists, The Oceanography Society is putting its policies where its mouth is, and now provides free membership to students and reduced-cost membership to early career scientists within three years of receiving their PhD degrees.

Accomplishing bottom-up planning demands time commitment. It requires volunteers to step up and funding agencies to cover costs. TOS is willing to partner in facilitating a planning processas a first step, perhaps we can engage in spirited discussion at this year's upcoming professional meetings worldwide. Let's get started!

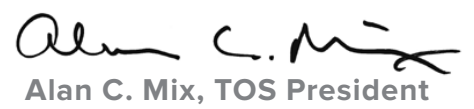

\section{REFERENCES}

Kennedy, H., and P. Liss. 2013. Scanning the Horizon: The Future Role of Research Ships and Autonomous Measurement Systems in Marine and Earth Sciences. The Challenger Society for Marine Science and the National Oceanography Centre (NOC) Association, UK, 31 pp, http://noc.ac.uk/files/ documents/about/2013_Scanning the Horizon.pdf. McDonough, N., and J.-B. Calewaert, eds. 2010. EurOcean 2010: Grand Challenges for Marine Research in the Next Decade. Conference Report and Ostend Declaration. Thermae Palace, Oostende, Belgium, October 12-13, 2010. Belgian Science Policy Office (BELSPO), Brussels. VLIZ Special Publication 49 Flanders Marine Institute (VLIZ), Oostende, Belgium, 57 pp, http://www.belspo.be/belspo/northsea/publ/ EurOCEAN2010_report_declaration.pdf. NRC (National Research Council). 2015. Sea Change: 2015-2025 Decadal Survey of Ocean Sciences. The National Academies Press, Washington, DC, 98 pp., https://doi.org/10.17226/21655. 